\title{
Cost-effectiveness and budget impact of a lifestyle intervention to improve cardiometabolic health in patients with severe mental illness
}

\author{
Anne Looijmans ${ }^{1,2}$, Frederike Jörg ${ }^{2,3}$, Richard Bruggeman ${ }^{2,4}$, Robert A. Schoevers ${ }^{4}$, Eva Corpeleijn ${ }^{5}$, Talitha L. Feenstra ${ }^{5-7}$, \\ A.D.I. (Thea) van Asselt ${ }^{5,8}$ \\ ${ }^{1}$ Department of Health Psychology, University Medical Center Groningen, University of Groningen, Groningen - The Netherlands \\ ${ }^{2}$ Rob Giel Research Centre, University Medical Center Groningen, University of Groningen, Groningen - The Netherlands \\ ${ }^{3}$ Research Department, Friesland Mental Health Services, Leeuwarden - The Netherlands \\ ${ }^{4}$ Department of Psychiatry, University Medical Center Groningen, University of Groningen, Groningen - The Netherlands \\ ${ }^{5}$ Department of Epidemiology, University Medical Center Groningen, University of Groningen, Groningen - The Netherlands \\ ${ }^{6}$ Faculty of Science and Engineering, Groningen Research Institute of Pharmacy, University of Groningen, Groningen - The Netherlands \\ ${ }^{7}$ National Institute for Public Health and the Environment (RIVM), Bilthoven - The Netherlands \\ ${ }^{8}$ Department of Health Sciences, University Medical Center Groningen, University of Groningen, Groningen - The Netherlands
}

\begin{abstract}
Introduction: This study assessed the cost-effectiveness and budget impact of a lifestyle intervention to improve cardiometabolic health in severe mentally ill (SMI) patients in the LION trial.

Methods: Patients $(n=244)$ were randomized to receive either care-as-usual or a lifestyle intervention in which mental health nurses coached patients in changing their lifestyle by using a web tool. Costs and quality of life were assessed at baseline and at 6 and 12 months. Incremental costs per centimeter waist circumference (WC) lost and per Quality-Adjusted Life Year (QALY) gained were assessed. Budget impact was estimated based on three intervention-uptake scenarios using a societal and a third-party payer perspective.

Results: Costs and reduction in WC were higher in the intervention $(n=114)$ than in the control $(n=94)$ group after 12 months, although not statistically significant, resulting in $€ 1,370$ per $\mathrm{cm}$ WC lost. QALYs did not differ between the groups, resulting in a low probability of the intervention being cost-effective in cost/QALY gained. The budget impact analysis showed that for a reasonable participation of $43 \%$, total costs were around $€ 81$ million over 5 years, or on average $€ 16$ million annually (societal perspective).

Conclusions: The intervention is not cost-effective at 12 months and the budget impact over 5 years is substantial. Possibly, 12 months was too short to implement the intervention, improve cardiometabolic health, and reduce care costs. Therefore, the incentive for this intervention cannot be found in short-term financial advantages. However, there may be benefits associated with lifestyle interventions in the long term that remain unclear.

Keywords: Budget impact analysis, Cardiometabolic risk, Cost-effectiveness, Lifestyle intervention, Mental health care, Severe mental illnesses
\end{abstract}

\section{Introduction}

Patients with a severe mental illness (SMI), such as schizophrenia or bipolar disorders, have a shortened life

Received: January 30, 2020

Accepted: June 19, 2020

Published online: December 14, 2020

Corresponding author:

Anne Looijmans

Department of Health Psychology

University Medical Center Groningen

Hanzeplein 1, PO box 30.001

9700 RB Groningen- The Netherlands

A.Looijmans@umcg.nl expectancy compared to the general population, with cardiovascular disease being the primary cause of death (1). This alarming health status is associated with the side-effects of patients' antipsychotic treatment, their mental illness, and lifestyle behaviors. Lifestyle interventions for SMI patients seem effective in reducing weight and improving cardiometabolic risk factors such as waist circumference (WC), fasting glucose, and triglycerides (2,3).

Despite the growing literature on the effect of lifestyle interventions on SMI patients' physical health, limited evidence exists on the cost-effectiveness of such interventions (4). A 10-week diet and physical activity intervention in patients living in sheltered housing was considered borderline cost-effective over a 20 years horizon in men but not in women, which was probably due to the limited improvements in body mass index (BMI) (5). The STRIDE intervention 
targeting diet and physical activity in SMI patients visiting community mental health $(\mathrm{MH})$ centers improved weight and fasting glucose levels after 12 months of intervention (6). Costs ranged from $\$ 4,365$ to $\$ 5,687$ ( $€ 3,501$ to $€ 5,461$ using a 2014 Purchasing Power Parity (PPP) rate [7] of 0.802) (8). Costs per kilogram weight reduction were estimated from $\$ 1,623$ to $\$ 2,114$ ( $€ 1,302$ to $€ 1,695)$. To our knowledge, no budget impact analyses (BIAs) are published.

Policy makers need information on the cost-effectiveness and BIA before implementing lifestyle interventions. We present the cost-effectiveness and BIA of the Lifestyle Interventions for severe mentally ill Outpatients in the Netherlands (LION) trial, a pragmatic, randomized controlled trial studying the effectiveness of a 12-month multidimensional lifestyle approach on cardiometabolic health in SMI patients $(9,10)$. $\mathrm{MH}$ nurses were trained in motivational interviewing and coached patients to improve lifestyle behaviors by using a web tool. The intervention did not significantly improve abdominal adiposity and other cardiometabolic risk factors, reducing the a priori probability of the intervention being cost-effective. However, we consider it relevant to report on the cost-effectiveness and budget impact of the LION trial, as it contributes to the understanding of costs and budget impact of lifestyle interventions in SMI patients.

\section{Methods}

\section{Patients and interventions}

In total, 244 SMI patients of 27 health care teams of five $\mathrm{MH}$ organizations in the Netherlands participated in the LION trial. Teams were clustered and randomized into intervention ( $n=17)$ or control $(n=10)$ arm. In the intervention arm, for each team, a number of $\mathrm{MH}$ nurses would implement the lifestyle intervention. $\mathrm{MH}$ nurses received one day of training on coaching skills and the use of the web tool "Traffic Light Method." After 3 months, they attended an evaluation session. Nurses invited patients to participate when the annual physical screening showed one or more increased metabolic risk factors: $W C>88 / 102 \mathrm{~cm}$ (females/males), BMI $>25 \mathrm{~kg} / \mathrm{m}^{2}$, fasting glucose levels $>5.6 \mathrm{mmol} / \mathrm{L}$, or $\mathrm{HbA} 1 \mathrm{c}>5.7 \%$ or $>39$ $\mathrm{mmol} / \mathrm{mol}$. Exclusion criteria were pregnancy, BMI $<19 \mathrm{~kg} / \mathrm{m}^{2}$, or physical impairment. Patients in the intervention group ( $n=140$ ) and nurses started working in the web tool during regular care visits, planned to take place on average once every 2 weeks. First, patients and nurses screened patients' lifestyle behavior and created a lifestyle plan with specific goals. Subsequently, patients and nurses systematically evaluated patients' progress in achieving the lifestyle goals for approximately 15 minutes during regular care visits for 6 months. Hereafter, patients and nurses mapped out lifestyle behaviors again, updated the lifestyle plan, and evaluated this plan for the next 6 months until the trial ended. Patients in the control group $(n=104)$ received care-as-usual, meaning that medical problems are tackled immediately according to protocol, while lifestyle guidance is provided upon request of the patients. The study protocol and results are presented elsewhere $(9,10)$.

\section{Cost-effectiveness analysis}

The cost-effectiveness analysis (CEA) had a time horizon of 1 year, equal to the duration of the trial. Outcomes were expressed as incremental costs per reduced centimeter WC and per Quality-Adjusted Life Year (QALY) gained, using an incremental cost-effectiveness ratio (ICER). The ICER indicates the extra costs for the intervention as compared to care-as-usual that should be invested to lose one $\mathrm{cm}$ in WC or gain one additional QALY. WC was measured by trained nurses and QALYS were based on utility scores calculated from the Short Form 6D (SF-6D) using the official SF-6D algorithm (11-13), assessed at baseline, and after 6 and 12 months of intervention.

\section{Budget impact analysis}

To calculate the budget impact on a 5-year time horizon, three scenarios were developed and costs were estimated from a societal and from a third-party payer perspective, according to Dutch guidelines (14). A dedicated Excel tool, developed by Professor Dr. M. Dijkgraaf (Academic Medical Center, Amsterdam) reflecting national (14) and international (15) BIA guidelines, was applied to perform these calculations. For the three scenarios, several assumptions were made concerning the uptake of the intervention:

1) Optimistic: it was assumed that all eligible SMI patients would apply the intervention in 2016, with newly incident patients using the intervention in the remaining years. This hence assumed an extreme uptake of $78.5 \%$, which is the percentage satisfying the inclusion criteria.

2) Realistic: the uptake of the intervention as observed during the trial period $5.1 \%$ of all individuals approached) was extrapolated to the entire Dutch SMI population and the whole period considered.

3) Intermediate: a gradual increase in participation of eligible patients was assumed, correcting for the persons refusing annual physical screenings (55.2\%), which was used to determine patients' eligibility. In this scenario, it was assumed that uptake increased from the $5.1 \%$ observed in the trial to $43 \%(78.5 \% * 55.2 \%)$ in the last year.

The number of SMI patients aged 15-65 in secondary care was estimated to range from $111,000(16)$ to $120,000(17,18)$. Incident SMI cases in care were estimated at 26,000 (16) or $6,500(18,19)$ depending on definition and on the percentage of schizophrenia in SMI (17). The percentages of uptake of the three scenarios were applied to both prevalence and incidence.

\section{Costs}

The CEA was conducted from a societal perspective, that is, including all relevant costs inside and outside $\mathrm{MH}$ care. Data on resource use and productivity losses were collected using a care consumption questionnaire (covering the previous 6 months) at baseline and after 6 and 12 months. Nurses helped patients to complete the questionnaire, possibly using patients' diaries or patient files for retrieving medical contacts. Data from the 6- and 12-month measurement 
were used to calculate total 1 year costs. Data collected at baseline were used for purposes of multiple imputation of missing data. Costing was performed according to Dutch guidelines for economic evaluation (20), see Appendix I (Available as supplementary material) for the cost categories and unit costs used. If no standard unit price was available, tariffs were used. Medication use was derived from patients' record forms, with prices assessed from the Dutch health care institute (21). All costs were expressed in euros for the year 2014.

For the BIA, unit prices were calculated both from a societal perspective, using unit prices as in the CEA, and from a third-party payer perspective using diagnosis treatment combination (DBC)-based tariffs (22). Because intervention costs were not yet coded in the DBC system, two alternative thirdparty approaches were used: (I) including costs based on official estimates for the intervention costs (training costs for coaches and costs of the web tool from seller's information) and no time costs for coaches and (II) including trial-based intervention-related costs and the time costs of the coaches when giving the intervention, valued at the average DBC tariff relevant for this patient group and assuming it takes additional time instead of replacement of other activities. These two variants were used to reflect the situation that the time costs of the intervention would not be reimbursed $(I$, from a third-party payer perspective no costs) or that the time costs would be fully reimbursed (II, hypothetical new tariff estimated based on average DBC tariff for this patient group).

\section{Intervention costs}

Intervention costs were distinguished in those for the web tool and its use, for training of the coaches, and the coaches' time while providing the lifestyle intervention. Training costs were determined based on the number of coaches trained and the number of participants per coach, which was 1.7. The costs per participant for the three perspectives are shown in Table I. Training costs were a one-off cost that does not need

TABLE I - Intervention costs (euros) per participant for societal and third-party payer perspectives

\begin{tabular}{lccc}
\hline Type of costs & $\begin{array}{c}\text { Societal } \\
\text { perspective }\end{array}$ & $\begin{array}{c}\text { Third-party } \\
\text { payer I }\end{array}$ & $\begin{array}{c}\text { Third-party } \\
\text { payer II }\end{array}$ \\
\hline $\begin{array}{l}\text { Web tool license } \\
\text { and use }\end{array}$ & $43^{*}$ & 63 & 63 \\
$\begin{array}{l}\text { Training of coaches } \\
\begin{array}{l}\text { Coaches' time } \\
\text { spent on lifestyle }\end{array}\end{array}$ & 51 & $134^{+}$ & $109^{+}$ \\
$\begin{array}{l}\text { intervention } \\
\text { Total costs per }\end{array}$ & 599 & $0^{\ddagger}$ & 917 \\
participant & 693 & 197 & 1089 \\
\hline
\end{tabular}

*In the societal perspective, license costs per participant were put to $€ 0$, since for a web tool, real costs are related to its development, not to its use. Annual license costs would cover these development costs.

${ }^{+}$In the third-party payer I perspective, costing of training of coaches was based on ideal training hours and ideal participation of coaches, while in II scenario II, trial-based costs were used.

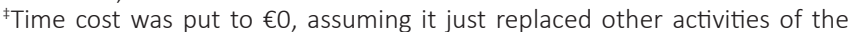
nurse and would not lead to an adaptation of the diagnosis treatment combination tariffs. any repetition in the next 5 years. As with enrolling new participants no additional training is required, costs after the first year are reduced. See Appendix II (Available as supplementary material) for detailed information about the intervention costs.

\section{Costing variants of BIA}

If the number of participants would increase to 25 per coach, training costs would reduce considerably to $€ 9.1$ (societal perspective), €7.4 and €3.5 (third-party payer perspective I and II, respectively), possibly affecting the budget impact. Therefore, a sensitivity analysis was performed with 25 participants per trained coach.

\section{Data analyses}

Missing data (25.1\%) were imputed five times using predictive mean matching in SPSS, version 22 (23) and the costs and effects were bootstrapped separately for each imputation dataset in Microsoft Excel 2010. Reported costs and effects after 12 months of intervention were pooled means of imputed datasets and confidence intervals were estimated with the percentile method (i.e., using 2.5th and 97.5th percentile as the lower and upper bound, respectively). Results of the bootstrap analyses are presented in incremental cost-effectiveness planes and cost-effectiveness acceptability curves (CEACs) (24). In the planes, the differences in costs are presented on the vertical axis and the differences in WC and QALYs on the horizontal axis. Dots in the lower right quadrant are most favorable for the intervention, indicating more effectiveness and less costs compared to the control condition. The CEACs indicate the probability that the intervention is cost-effective, given societal willingness to pay for $1 \mathrm{~cm}$ reduction in WC or one QALY gained. In sensitivity analyses, CEACs are explored for persons with complete data. Budget impact estimates were calculated by multiplying projected numbers of participants in the different uptake scenarios with per-participant costs and adding over the 5-year time horizon.

\section{Results}

In total, 114 patients in the intervention group and 94 patients in the control group had data on costs or the SF-6D on at least one measurement and were included in the economic evaluation. Table II presents the demographic characteristics of these participants.

\section{Cost-effectiveness analyses}

The mean WC in the intervention group decreased 0.47 $\mathrm{cm}$ after 12 months of intervention compared to a $1.37 \mathrm{~cm}$ increase in the control group, although this difference was not statistically significant (Tab. III). The difference in QALYs between intervention and control group was negligible (0.001). The mean societal costs in the intervention group were $€ 2,516$, higher than in the control group, but not statistically significantly so. 
TABLE II - Demographic characteristics of study participants

\begin{tabular}{|c|c|c|c|c|c|}
\hline & $\mathbf{N}$ & Total & Intervention group & Control group & p-values \\
\hline \multicolumn{6}{|l|}{ General information } \\
\hline Teams & & 27 & 17 & 10 & \\
\hline Patients & & 208 & 114 & 94 & \\
\hline Age (years) & 208 & $46.7 \pm 10.4$ & $45.0 \pm 10.4$ & $48.7 \pm 10.0$ & 0.01 \\
\hline \multicolumn{6}{|l|}{ Waist circumference (cm) } \\
\hline Male & 96 & $111.6 \pm 12.5$ & $112.9 \pm 14.4$ & $110.2 \pm 10.0$ & 0.29 \\
\hline Female & 104 & $109.3 \pm 16.3$ & $111.1 \pm 17.1$ & $107.0 \pm 15.0$ & 0.21 \\
\hline Body mass index (BMl; kg/m²) & 193 & $32.1 \pm 6.5$ & $32.9 \pm 7.5$ & $31.1 \pm 5.1$ & 0.04 \\
\hline
\end{tabular}

Data are presented as $\mathrm{N}(\%)$ or mean \pm standard deviation. P-values in bold present p-values below 0.05 .

*Diabetes was defined based on reported diagnosis of diabetes, use of antihyperglycemic medication, fasting glucose $\geq 7.1 \mathrm{mmol} / \mathrm{L} \mathrm{or} \mathrm{HbA1c} \geq 48 \mathrm{mmol} / \mathrm{mol}$.

TABLE III - Pooled mean QALYs, reduced WC and costs for intervention and control group after 12 months of intervention

\begin{tabular}{|c|c|c|c|}
\hline & Control $(n=94)$ & Intervention $(n=114)$ & Difference $(95 \% \mathrm{Cl})^{*}$ \\
\hline Change in WC after 6 months $(\mathrm{cm})^{+}$ & -0.096 & -0.974 & $-0.878(-1.518 ; 4.144)$ \\
\hline Change in WC after 12 months $(\mathrm{cm})^{+}$ & 1.370 & -0.466 & $-1.836(-0.617 ; 4.264)$ \\
\hline Baseline & 0.686 & 0.689 & 0.003 \\
\hline 6 months & 0.679 & 0.677 & -0.002 \\
\hline \multicolumn{4}{|l|}{ Costs } \\
\hline Intervention & NA & $€ 693$ & $€ 693$ \\
\hline Medication & $€ 564$ & $€ 656$ & $€ 92$ \\
\hline Admission & $€ 2,527$ & $€ 2,637$ & $€ 110$ \\
\hline Psychiatric care at home & $€ 902$ & $€ 683$ & $-€ 219$ \\
\hline Sheltered living & $€ 8,735$ & $€ 12,668$ & $€ 3,933$ \\
\hline GP, alternative healer, etc. & $€ 965$ & $€ 656$ & $-€ 309$ \\
\hline Day care center & $€ 258$ & $€ 334$ & $€ 76$ \\
\hline Paid household help & $€ 1,239$ & $€ 1,294$ & $€ 55$ \\
\hline Informal care & $€ 792$ & $€ 886$ & $€ 94$ \\
\hline Productivity loss unpaid work & $€ 8,333$ & $€ 5,722$ & $-€ 2,611$ \\
\hline Productivity loss paid work & $€ 3,928$ & $€ 5,705$ & $€ 1,777$ \\
\hline Total mean societal costs & $€ 33,187$ & $€ 35,703$ & $€ 2,516(-€ 12,592 ; € 17,423)$ \\
\hline
\end{tabular}

$\mathrm{A} \& \mathrm{E}=$ accident and emergency; $\mathrm{Cl}$ = confidence interval; GP = general practitioner; NA = not applicable; QALY = Quality Adjusted Life Year; SF-6D = Short Form 6D; $\mathrm{WC}=$ waist circumference.

*95\% Cl only available for main categories as no bootstrap analyses was performed on subcategories.

${ }^{+}$Change in WC is calculated as the WC at 6 or 12 months minus baseline WC. Negative scores indicate a reduction in WC. 


\section{Costs per reduced $\mathrm{cm}$ WC and gained QALY}

The ICER indicated a cost of $€ 1,370$ per cm reduction in WC (€2,516/1.836). The intervention seems more effective but also more costly than the control condition (Fig. 1A, right upper quadrant), although there is considerable uncertainty about the costs and effects, as the cloud covers the origin of the axes. Because a reference value for societal willingness to pay for $1 \mathrm{~cm}$ reduction in WC is lacking, it is difficult to conclude whether the intervention can be considered cost-effective. The CEAC (Fig. 2A) shows that at an assumed threshold of $€ 6,000$ per $\mathrm{cm}$ WC reduction, the intervention is considered cost-effective in $75 \%$ of the cases. With regard to QALYs, great uncertainty exists over the costs and benefits of the intervention compared to control as the bootstrapped cost-effectiveness pairs are quite evenly distributed over all four quadrants (Fig. 1B). Because the difference in QALYs between intervention and control group was almost zero, it was not useful to calculate an ICER. The probability of the intervention being cost-effective with regard to QALYS is around $40 \%$ for the whole range of thresholds explored (Fig. 2B).

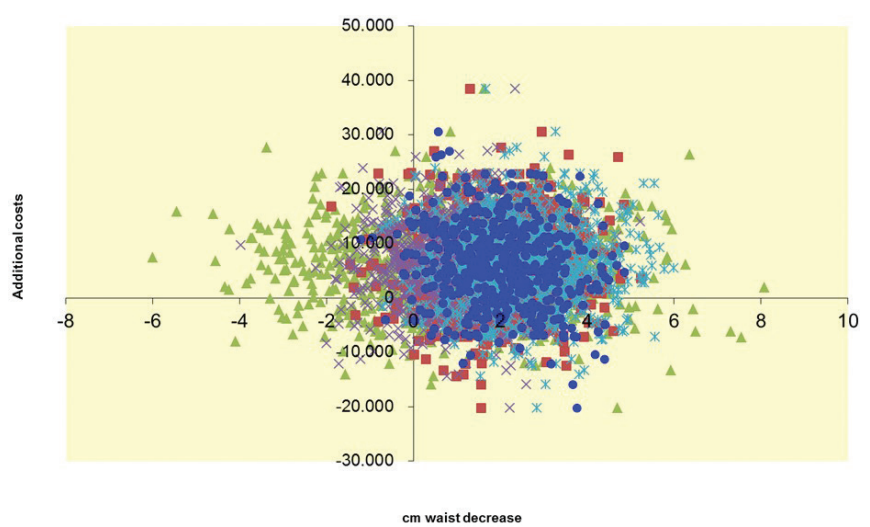

(A)

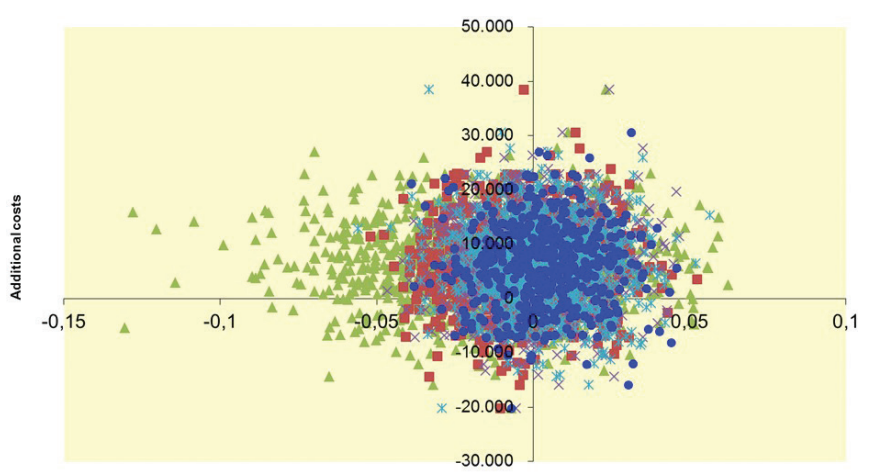

(B)

Fig. 1 - Incremental cost-effectiveness plane for (A) costs per $\mathrm{cm}$ reduction in waist circumference and (B) costs per gained QualityAdjusted Life Year (QALY). The different sets of dots represent the five sets of imputed data.

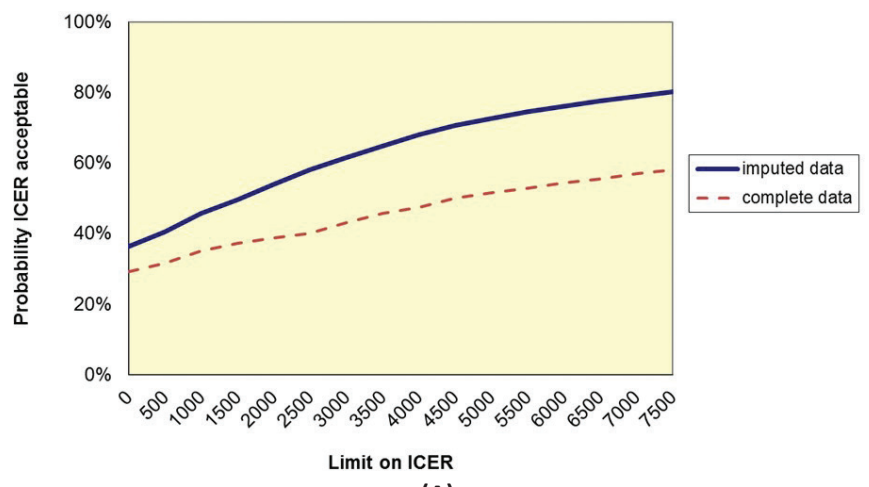

(A)

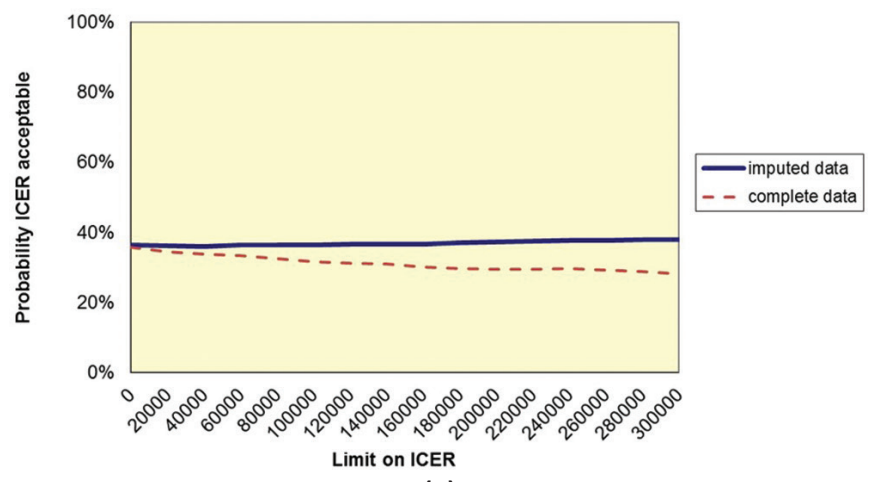

(B)

Fig. 2 - Cost-effectiveness acceptability curves for (A) costs per $\mathrm{cm}$ reduction in waist circumference and (B) costs per gained Quality Adjusted Life Year (QALY), for imputed and complete data.

\section{Complete data}

Complete data on WC and costs (24 intervention patients; 31 control patients) and on QALYs and costs (18 intervention patients; 28 control patients) were limited. Although this increases uncertainty, outcomes are comparable to outcomes based on imputed data (dashed lines in Fig. 2A, B).

\section{Budget impact analysis}

The first column in Table IV presents the numbers of participants as a result of applying the percentages of uptake of the three scenarios to both prevalence and incidence. Budget impact estimates varied considerably depending on perspective and scenario (Tab. IV). They were smallest for the third-party payer perspective ignoring time costs (I) and largest for the third-party payer perspective when assuming all time costs were actually reimbursed (II). For a realistic uptake, the budgetary consequences from societal perspective were relatively modest at $€ 8$ million in total or $€ 0.9$ million annually after the first year. But this also meant that the actual use of the intervention was limited to just $5 \%$ of the incident population after the first year, which is a fraction of the almost $80 \%$ that would qualify based on lifestyle risk factors. Taking into account the refusal rates for annual physical screenings, a percentage of participation of $43 \%$ should be 
TABLE IV - Results of the budget impact analysis for three scenarios from three perspectives in million euros, based on price levels of 2014

\begin{tabular}{|c|c|c|c|c|c|}
\hline & & & \multicolumn{3}{|c|}{ Perspective } \\
\hline & & & Societal & $\begin{array}{l}\text { Third- } \\
\text { party } \\
\text { payer I }\end{array}$ & $\begin{array}{l}\text { Third- } \\
\text { party } \\
\text { payer II }\end{array}$ \\
\hline & \multicolumn{2}{|c|}{$\begin{array}{c}\text { Costs per participant } \\
(€)\end{array}$} & 693 & 197 & 1.089 \\
\hline \multirow[t]{2}{*}{ Scenario } & Year & $\begin{array}{l}\text { Numbers of } \\
\text { participants }\end{array}$ & \multicolumn{3}{|c|}{$\begin{array}{l}\text { Budget impact in the } \\
\text { Netherlands }\end{array}$} \\
\hline & & & \multicolumn{3}{|c|}{$€^{*}$ million } \\
\hline \multicolumn{6}{|c|}{ 1: Rapid roll out } \\
\hline & 2016 & 97,340 & 67 & 19 & 106 \\
\hline & 2017 & 20,410 & 14 & 4.0 & 22 \\
\hline & 2018 & 20,410 & 14 & 4.0 & 22 \\
\hline & 2019 & 20,410 & 14 & 4.0 & 22 \\
\hline & 2020 & 20,410 & 14 & 4.0 & 22 \\
\hline & $\begin{array}{l}5 \text { years } \\
\text { total }\end{array}$ & 178,980 & 124 & 35 & 195 \\
\hline \multicolumn{6}{|c|}{ 2: Uptake as in trial } \\
\hline & 2016 & 6,337 & 4.4 & 1.3 & 6.9 \\
\hline & 2017 & 1,329 & 0.9 & 0.3 & 1.5 \\
\hline & 2018 & 1,329 & 0.9 & 0.3 & 1.5 \\
\hline & 2019 & 1,329 & 0.9 & 0.3 & 1.5 \\
\hline & 2020 & 1,329 & 0.9 & 0.3 & 1.5 \\
\hline & $\begin{array}{c}5 \text { years } \\
\text { total }\end{array}$ & 11,651 & 8.1 & 2.3 & 12.7 \\
\hline \multicolumn{6}{|c|}{ 3: Gradual increase in uptake } \\
\hline & 2016 & 6,337 & 4.4 & 1.3 & 6.9 \\
\hline & 2017 & 19,260 & 13 & 3.8 & 21 \\
\hline & 2018 & 28,068 & 20 & 5.5 & 31 \\
\hline & 2019 & 31,787 & 22 & 6.3 & 35 \\
\hline & 2020 & 30,811 & 21 & 6.1 & 34 \\
\hline & $\begin{array}{l}5 \text { years } \\
\text { total }\end{array}$ & 116,263 & 81 & 22.9 & 127 \\
\hline
\end{tabular}

Third-party approach (I) including the true intervention-related costs: training costs for coaches and costs of the web tool; third-party approach (II) including true intervention-related costs and the time costs of the coaches when giving the intervention. Numbers do not completely add to 5 year totals due to rounding.

possible and would be an aim for actual implementation. In that case, budgetary impact could increase to around $€ 81$ million over 5 years, or on average $€ 16$ million annually. This 16 million would be $0.08 \%$ of the total annual spending on mental disorders in the Netherlands or $0.02 \%$ of the total health care budget (in 2011) (25).

The sensitivity analysis using training costs based on 25 participants per coach showed that training costs only impacted the third-party payer perspective that ignored time costs of nurses, see Appendix III (Available as supplementary material). For the other two perspectives, these time costs dominated costs per participant and hence a change in training costs would not matter much.

\section{Conclusions}

There is a need to implement effective lifestyle interventions in $\mathrm{MH}$ care practice to improve SMI patients' physical health, but related economic evaluations are limited. The current study presents the cost-effectiveness and BIAs of a 12-month multidimensional lifestyle intervention using a web tool in SMI patients. Our results showed a cost of $€ 1,370$ per centimeter reduction in WC. Since a reference value for societal willingness to pay is lacking, it is hard to conclude whether this could be considered cost-effective. No differences in QALYs were found between intervention and control group after 12 months. Given the higher costs in the intervention group, this would drastically reduce the probability of the intervention being cost-effective in terms of QALYs. No costs per QALY were calculated, as the ICER would be substantially above any threshold.

Two previous CEAs showed that lifestyle interventions for SMI patients were not considered cost-effective, mainly as a result of lacking improvements in clinical outcomes and the higher intervention costs $(26,27)$. This is comparable to the LION intervention; the a priori probability of being costeffective was considered low given the lack of significant improvements in abdominal obesity or cardiometabolic health (10). The STRIDE intervention did significantly decrease patients' weight after 12 months, and costs to reduce $1 \mathrm{~kg}$ in weight ranged from $\$ 1,623$ to $\$ 2,114$ (€1,302 to $€ 1,695)$ (8). However, the health effects diminished after 24 months (28). When effective, lifestyle interventions in SMI patients mostly lead to small physical health improvements, and sustaining these improvements in the long term is a challenge (2). The difficulty with these lifestyle interventions is that large costs need to be made to achieve small changes in physical health, but the potential budget gains are in the long term and the amplitudes of these gains are yet unknown.

The lack of improvements in QALYs after 12 months of intervention was reported previously in SMI patients $(5,26,27)$ and is a phenomenon observed more often in $\mathrm{MH}$ studies in general. In the SMI population, it might be especially challenging to improve quality of life (QoL) via lifestyle interventions, and it is even likely that QoL decreases as a result of acknowledging the poor health status and experiencing barriers in achieving a healthy lifestyle (29). QoL may be impacted much heavier by (changes in) the underlying $\mathrm{MH}$ condition than by whether or not the patient is undergoing a lifestyle intervention. If any improvements in QoL were to be found, these would be on the long run, when somatic comorbidities are prevented.

The intervention uptake in the trial was low (5.1\%). A 12-month implementation period might be too short for $\mathrm{MH}$ care organizations to properly facilitate $\mathrm{MH}$ nurses to embed this intervention in their daily clinical care routines. In the field of diabetes, for example, lifestyle interventions take between 3 and 6 years $(30,31)$. Better imbedding could increase the 
use of the program, thereby enlarging the number of targeted patients, leading to a higher intervention uptake.

For the current intervention to achieve a final coverage rate of $43 \%$ of the SMI population, a net societal investment of around 16 million annually for the following 5 years is needed. This is about $0.08 \%$ of the annual budget spent on mental disorders in the Netherlands. The benefit of this intervention cannot be found in a short-term financial advantage of its implementation. Rather, the unmet needs of the patient population to improve physical discomfort and potential long-term health gains should be valued.

When the intervention could be implemented within regular DBCs, budgets of $\mathrm{MH}$ care organization are only increased by the additional costs related to training of staff and the license for the web tool, resulting in relative low intervention costs (€693). However, because the web tool is delivered by a commercial party and costs were calculated per person, costs could increase rapidly. Collectively buying the web tool for all $\mathrm{MH}$ care organizations would yield room for negotiation on costs and thereby positively affect budgets.

\section{Limitations}

A first limitation of the study is the large amount of missing data. Whereas most data in the LION trial were gathered as part of standard care, an additional effort had to be made to fill out the cost questionnaire and the SF-6D. Second, for the $\mathrm{BIA}$, costs per participant were calculated as a onetime cost in a 5-year period. However, it can be considered useful to repeat (parts of) the intervention within this 5-year period to maintain possibly achieved lifestyle changes, increasing the costs per participant. On the contrary, repetition can also improve physical outcomes. Third, in the scenario of gradual increase in intervention uptake, a maximum of $43 \%$ of all SMI patients in the Netherlands were targeted within a 5-year period. Still, more than half of the patients will not receive the intervention. It can be expected that the inclusion of the remaining patients in a lifestyle intervention is especially difficult, increasing the number of nurse hours even before the start of the intervention. If the remaining patients would be actively targeted for the intervention, the impact on the national budget will be much larger. Fourth, the type of patients in the intervention and control group might have been different. This assumption was based on the large differences in costs noticed between intervention and control group with respect to their living situation (residential yes/no) and jobs (paid/ unpaid). However, this is not considered to drastically change conclusions about cost-effectiveness since these were predominantly driven by the lack of clinical effects.

\section{Summary}

Lifestyle interventions mostly lead to small improvements in patients' physical health whereas costs are often higher than standard care. In the short term, lifestyle interventions in SMI patients may not seem cost-effective. However, small improvements in the short term may translate into larger health gains over a lifetime, and so cost-effectiveness may turn out to be more favorable in the end. To build this case, we first need more solid evidence that lifestyle interventions are indeed (cost)-effective, especially in the long term.

\section{Acknowledgments}

We are grateful to Professor Dr. M. Dijkgraaf (Academic Medical Center, Amsterdam) for letting us use the BIA tool he constructed.

\section{Disclosures}

Conflict of interest: The authors declare no conflict of interest. Financial support: This work was supported by ZonMw (grant number 837001006$)$. The funding source had no influence on the study design; in the collection, analysis, and interpretation of the data; in the writing of the report; and in the decision to submit the paper for publication.

\section{References}

1. De Hert M, Correll CU, Bobes J, et al. Physical illness in patients with severe mental disorders. I. Prevalence, impact of medications and disparities in health care. World Psychiatry. 2011;10(1):52-77.

2. Bruins J, Jörg F, Bruggeman R, Slooff C, Corpeleijn E, Pijnenborg $M$. The effects of lifestyle interventions on (long-term) weight management, cardiometabolic risk and depressive symptoms in people with psychotic disorders: a meta-analysis. PLoS One. 2014; 9(12):e112276

3. McGinty EE, Baller J, Azrin ST, Juliano-Bult D, Daumit GL. Interventions to address medical conditions and health-risk behaviors among persons with serious mental illness: a comprehensive review. Schizophr Bull. 2016;42(1):96-124.

4. Verhaeghe N, De Maeseneer J, Maes L, Van Heeringen C, Annemans L. Effectiveness and cost-effectiveness of lifestyle interventions on physical activity and eating habits in persons with severe mental disorders: a systematic review. Int J Behav Nutr Phys Act. 2011;8(1):28.

5. Verhaeghe N, De Smedt D, De Maeseneer J, Maes L, Van Heeringen C, Annemans L. Cost-effectiveness of health promotion targeting physical activity and healthy eating in mental health care. BMC Public Health. 2014;14(1):856.

6. Green CA, Yarborough BJH, Leo MC, et al. The STRIDE weight loss and lifestyle intervention for individuals taking antipsychotic medications: a randomized trial. Am J Psychiatry. 2015;172(1): 71-81.

7. Organisation for Economic Co-operation and Development (OECD). http://www.oecd.org. Updated 2017.

8. Meenan RT, Stumbo SP, Yarborough MT, Leo MC, Yarborough $\mathrm{BJH}$, Green CA. An economic evaluation of a weight loss intervention program for people with serious mental illnesses taking antipsychotic medications. Adm Policy Ment Health. 2016; 43(4):604-615.

9. Looijmans A, Jörg F, Bruggeman R, Schoevers R, Corpeleijn E. Design of the Lifestyle Interventions for severe mentally ill Outpatients in the Netherlands (LION) trial; a cluster randomised controlled study of a multidimensional web tool intervention to improve cardiometabolic health in patients with severe mental illness. BMC Psychiatry. 2017;17(1):107.

10. Looijmans A, Jörg F, Bruggeman R, Schoevers R, Corpeleijn E. Multimodal lifestyle intervention using a web-based tool to improve cardiometabolic health in patients with serious mental illness: results of a cluster randomized controlled trial (LION). BMC Psychiatry. 2019;19(1):339. 
11. Brazier JE, Roberts JJMc. The estimation of a preference-based measure of health from the SF-12. Med Care. 2004;42(9): 851-859.

12. Kharroubi SA, Brazier JE, Roberts J, O'Hagan A. Modelling SF$6 \mathrm{D}$ health state preference data using a nonparametric Bayesian method. J Health Econ. 2007;26(3):597-612.

13. McCabe C, Brazier J, Gilks P, et al. Using rank data to estimate health state utility models. J Health Econ. 2006;25(3):418-431.

14. Nederland DZ. Richtlijn voor het uitvoeren van economische evaluaties in de gezondheidszorg. 2016.

15. Sullivan SD, Mauskopf JA, Augustovski F, et al. Budget impact analysis-principles of good practice: report of the ISPOR 2012 Budget Impact Analysis Good Practice II Task Force. Value Health 2014;17(1):5-14.

16. Statline from Statistics Netherlands (CBS), July 2016; http:// statline.cbs.nl/Statweb/

17. Delespaul P. Consensus over de definitie van mensen met een ernstige psychische aandoening (EPA) en hun aantal in Nederland. Tijdschrift voor psychiatrie, 2013.

18. van Alphen A, Ammeraal M, Blanke $C$, et al. Multidisciplinaire richtlijn schizofrenie. 2012. Versie 2.0. Trimbos instituut.

19. Boonstra N, Wunderink L, de Wit PHM, Noorthoorn E, Wiersma D. De administratieve incidentie van niet-affectieve psychosen in Friesland en Twente. Tijdschrift voor Psychiatrie. 2008;50(10):637.

20. Hakkaart-van Roijen L, van der Linden N, Bouwmans C, Kanters T, Tan SS. Kostenhandleiding. Methodologie van kostenonderzoek en referentieprijzen voor economische evaluaties in de gezondheidszorg In opdracht van Zorginstituut Nederland Geactualiseerde versie. 2015.

21. Nederland Zorginstituut [Dutch Care Institute], July 2016; www.medicijnkosten.nl.
22. Oostenbrink JB, Rutten F. Cost assessment and price setting of inpatient care in the Netherlands. The DBC case-mix system. Health Care Manag Sci. 2006;9(3):287-294.

23. IBM Corp., IBM SPSS Statistics for Windows, Version 22.0. Armonk, NY: IBM Corp. 2013.

24. Van Hout BA, Al MJ, Gordon GS, Rutten FF. Costs, effects and C/E-ratios alongside a clinical trial. Health Econ. 1994;3(5): 309-319.

25. RIVM Cost of Illness database, 2013; www.costofillness.nl.

26. Heslin M, Patel A, Stahl D, et al. Randomised controlled trial to improve health and reduce substance use in established psychosis (IMPaCT): cost-effectiveness of integrated psychosocial health promotion. BMC Psychiatry. 2017;17(1):407.

27. Holt RI, Hind D, Gossage-Worrall R, et al. Structured lifestyle education to support weight loss for people with schizophrenia, schizoaffective disorder and first episode psychosis: the STEPWISE RCT. Health Technol Assess. 2018;22(65):1.

28. Green CA, Yarborough BJH, Leo MC, et al. Weight maintenance following the STRIDE lifestyle intervention for individuals taking antipsychotic medications. Obesity. 2015;23(10):1995-2001.

29. Stiekema AP, Looijmans A, van der Meer L, et al. Effects of a lifestyle intervention on psychosocial well-being of severe mentally ill residential patients: ELIPS, a cluster randomized controlled pragmatic trial. Schizophr Res. 2018;199:407-413.

30. Tuomilehto J, Lindström J, Eriksson JG, Valle TT. Prevention of type 2 diabetes mellitus by changes in lifestyle among subjects with impaired glucose tolerance. N Engl J Med. 2001;344(18):1343-1350.

31. Knowler WC, Barrett-Connor E, Fowler SE, et al.; Diabetes Prevention Program Research Group. Reduction in the incidence of type 2 diabetes with lifestyle intervention or metformin. N Engl J Med. 2002;346(6):393-403. 